\title{
The Meaning and Connotation of the 2011 Plan to Promote Innovation Ability for College
}

\author{
Yi ZHU, Qingling LIAO*, Chun LIU, Xiuying WANG, Min WANG \\ Wuhan Technology and Business University, Wuhan, Hubei, 430065, China
}

\begin{abstract}
In order to speed up the construction of an innovative country, and deepen the reform of scientific research system, the Ministry of Education and the Ministry of Finance jointly implement a plan to promote the innovation ability of college. This is a strategic choice to solve the backward science and technology system, to improve the quality of higher education, and to promote the mechanism reform of China's science and technology and higher education system. We should have a deep understanding of the core connotation in the implementation of the "2011 plan", to grasp the new development opportunity, to carry out collaborative innovation, and to comprehensively promote the innovation ability. Promoting institutional mechanisms reform and constructing collaborative innovation system led by college, so as to promote the trinity innovation ability of talent, discipline and research.
\end{abstract}

KEYWORD: College; Innovation ability; 2011 plan

In order to strengthen the construction of an innovative country, in March, 2012, the Ministry of Education and the Ministry of Finance issued the comments on the implementation of the 2011 plan to raise the innovation ability of higher school. The implementation of the "2011 plan" is an effective way to speed up the construction of an innovative country and a strategic action to deepen the reform of scientific research system. Wuhan technology and business university have set up a Collaborative Innovation Center of Modern Logistics and Commerce in Hubei Province, which has won the appraisal of "Hubei Province 2011 plan" leading group and into the building of the provincial foster collaborative innovation center. Therefore, we will do some preliminary study on the significance and connotation of the 2011 plan.

\section{TO CARRY OUT COLLABORATIVE INNOVATION IS A STRATEGIC CHOICE FOR THE DEVELOPMENT OF COLLEGE}

College have the advantages of comprehensive set of disciplines, concentrated talents, and intensive research efforts, their role is gradually prominent in collaborative innovation chain. Actively promoting the collaborative innovation to make the different subjective to play role in collaborative innovation chain. It has become an important strategy for the higher education future development.

\subsection{To carry out collaborative innovation is conducive to resolving the problem that technology system lags behind the national strategic demand}

Scientific research institutions in China are mainly composed of universities, research institutes, enterprises research and development institutions which basic research, applied research, technology development are mutually disjointed and higher institutions and scientific research are discrete. Innovative talents cultivation and science and technology innovative activities are separated. Solving the national strategic needs to carry out collaborative innovation, to create innovative strategic alliance, and to make a breakthrough in frontier fields and key technologies.

\subsection{To carry out collaborative innovation is conducive to comprehensively improving the quality of higher education}

College occupied an important position in the construction of innovative country. The closed and

Zhu Yi (1977-), male, master, lecturer, Wuhan Technology and Business University, Wuhan 430071, The 2013 scientific research special project (S2013006) : the current situation and countermeasures of the scientific research work of private colleges and universities in Hubei. *Corresponding author 
inefficient phenomenon on science and technology innovation does not match with national demand and disconnect with talent training and so on. With the national demand to vigorously carry out collaborative innovation, its organization pattern and platform was explored by the cooperation and association from building mechanism to realize talents, discipline and scientific research trinity development. All of these can effectively promote the innovation ability of college and improve the quality of higher education.

\subsection{To carry out collaborative innovation is conducive to promoting the reform of China's science and technology and higher education}

For a long term, China's innovation powers all have their own system which leads to the dispersion and duplication of innovation resources and low innovation efficiency. It should promote the system and mechanism reform to break the boundaries of industry, region and sector to effectively improve the integrating ability of technological resources and the organizing ability. It will build up a innovation system and network to promote the collaborative innovation of all kinds of social innovation powers, to promote the integrating development and improve the country's overall innovation ability and competitive strength.

Higher education scientific research in China has not effectively promoted the quality improvement of talent cultivation. The "Qian Xuesen question" is essentially the profound reform requirement on science and technology system and higher education. Collaborative innovation will inevitably promote the great change of China's science and technology system, finally to realize the construction target of an innovative oriented country and to enhance the leading role of China in the international field.

\section{PROFOUND UNDERSTANDING ON THE CORE CONNOTATION IN THE IMPLEMENTATION OF THE "2011 PLAN"}

\subsection{The reform innovation of the existing system and mechanism of higher education is the core connotation of "2011 plan"}

The concept of university-industry collaboration has been advocated by the governments at all levels and pushed through for nearly twenty-five years before the "collaborative innovation" philosophy putted forward by the general secretary $\mathrm{Hu}$ Jintao. However, there are essential differences between them. The university-industry collaboration is not to break the inherent obstacles of mechanism and system. College has always maintained a contractual relationship as Party A and Party B with their partners which are unable to form a mutual fusion community of interests. The collaborative innovation essence is from advocating the system innovation to create a Cooperative Innovation Alliance and to establish a win-win situation and unit in strategic alliance.

The system and mechanism reform of higher education not only need the university leadership wisdom and courage, but also need strong support from education administrative department and all sectors of society. The full implementation of the "2011 plan" is actually the "innovation drive and transition development" of Chinese higher education. The traditional college will not deeply experience the spiritual essence of "collaborative innovation" and not walk on a comprehensive and innovative road of colleges system and mechanism reform, which will inevitably gradually fall behind in the great development era of innovation.

\subsection{Depth fusion of personnel training and scientific research is the characteristics of "2011 plan"}

Personnel training and scientific research are the two basic functions of college. The "2011 plan" is promoted by college as the main body, its main implement route is fusion of talents cultivation and scientific research. On January 9, 2006, the general secretary $\mathrm{Hu}$ Jintao announced at the National Science and Technology Conference that China's technology development objectives in the next 15 years is to establish the innovative country in 2020 . The cornerstone of the innovation oriented country is a large number of high level creative talents. At present China's higher education personnel does not meet this quality demand. University can absorb, gather, and reorganize various innovation resources and innovation strength by the 2011 Collaborative Innovation Plan, the level of innovative talent training is greatly enhance and meet the human resource demand of innovation oriented country. University should avoid restricting the scientific research ability enhancement and bases construction, while it should keep the cultivation of innovative talents and then to realize the complementary and coordinated development of teaching and scientific research. The university should set up a fusion target to realize common development of the personnel training and scientific research.

\subsection{The focus on industry area and target location is the key to the success of "2011 plan"}

The "2011 plan" implemented by the Ministry of Education and the Ministry of Finance is divided into four project categories respectively oriented by scientific frontier, industry, regional development and cultural inheritance and innovation with "national urgent need, international first-class" as criteria, which is a very scientific policy project. 
Establishment clear construction theme is the key breakthrough, university can be successful in five years of "2011 plan" construction period. If the "2011 plan" is large and general, it will result in duplication investment in projects and malignant disorder competition inevitably. Especially the core aim of "2011 plan" is the system and mechanism innovation, the reform is difficult for involving a wide range and complicated interest relations, if the target is set in multiple disciplines, multiple industries and regions, the possibility to complete the reform in a short term is greatly reduced.

Collaborative innovation should be highly focused. It is easy to realize the reform and innovation of university system and mechanism. The communication and coordination between alliance members would maintain unobstructed. The reform operability is greatly enhanced.

\subsection{The international knowledge gradient transfer is the security element for the "2011 plan" to be in line with international standards}

Following the investment gradient transfer and industrial gradient transfer, knowledge gradient transfer is becoming a world trend. College should actively learn from international experience and absorb international factors. The Collaborative Innovation Strategic Alliance should meet the three premises, one is the international partners should be highly consistent with the focused discipline and industry of Collaborative Innovation Alliance; two is the international partners has a long-term close cooperation relations with the led university; three is the international partners and the led university have materialized cooperation mechanism for collaborative innovation projects.

\section{3 "2011 PLAN" IS A NEW DEVELOPMENT OPPORTUNITY FOR PRIVATE COLLEGE}

With the coming of knowledge economy, scientific research innovation has become the soul of modern higher education increasingly. However, private college is on a disadvantageous position in scientific research innovation. They have not formed their own research strengths and strong discipline. The main reasons are the lack of a number of full-time scientific research innovation teacher team with high efficiency and competence, a serious shortage of scientific research funds, and the apparent lack of foreign academic exchange and teaching practice.

"2011 plan" is the new opportunity for the development of private university. College should change the idea and update the concept and put the collaborative innovation in the strategic position for the school's future development. They should build a strong discipline and create their own research team. They should encourage teachers to participate in the practical implementation, they should invest funds into the scientific research vigorously and reward amply to outstanding teachers on innovation achievements. Scientific research innovation is the most important driving force in formation and improvement of the core competitiveness. If private college attach great importance and practice collaborative innovation, they can stand in an invincible position and even integrate into the firstclass universities list in the future.

\section{CARRYING OUT COLLABORATIVE INNOVATION TO PROMOTE THE INNOVATION ABILITY}

College should face the important national demands, combine with the overall school talent, discipline and research development to form a classified implementation and systematic promotion working mechanism. College should take demand orientation and mission traction, center on global scientific frontier and regional country demand, deepen reform of system and mechanism to form some international leading disciplines with significant characteristics and a group of research fields with international influence.

\subsection{First try first pilot, actively cultivate and form collaborative innovation institutions}

To carry out the cultivation work of collaborative innovation institutions can be according to the open declaration, expert reviewing, approving procedures. It mainly focuses on its direction determination, institution formation, innovation resources and factors aggregation, innovation environment and atmosphere construction, and then it will gradually form a new platform and a new mechanism.

College should play the advantage of location and discipline characteristic, choose the key field and the characteristic direction, actively integrate resources, effectively play the agglomeration effect, cultivate the innovation platform to form 2011 collaborative innovation training center. College can make full use of the existing scientific research institutions to carry out collaborative innovation through extensive combination with research institutes enterprises and other industries with similar or complementary advantage subjects, to attract and gather international high quality resources and excellent innovative team, to establish a knowledge innovation mode in line with international practice and to create a good academic environment and atmosphere. College can set a coordination innovation center integrating personnel, disciplines and research. 


\subsection{To promote reform and construct a \\ collaborative innovation system led by college}

With the development demand of the science frontiers and the demand of national development, college should focus on the establishment of continuous innovation research organization model, exploring the collaborative innovation of personnel management and forming an evaluation mechanism oriented by innovation quality and contribution, optimizing cross subject fusion oriented resource allocation, innovating international exchanges and cooperation model, creating culture environment.

\subsection{Promote the trinity innovation ability of talent, discipline, and scientific research}

College will focus on important scientific issues and the great demand of the country, with scientific research as the support, with subject as the base, with talent as the foundation, to enhance the cooperation and interaction among the three and to promote the management system, to establish collaborative innovation strategic alliance by depth cooperation with other college, scientific research institutions, enterprises; to promote resource sharing, jointly develop major scientific research projects, achieve substantial achievement in the key fields.

College should use the management reform to vigorously promote collaborative innovation reform organization and personnel management, personnel training and assessment, research and resource allocation mode and innovation culture construction, to form comprehensive reform experimentation area, to create environment for innovation and realize the trinity comprehensive enhancement of innovation ability in talent, discipline and research.

\section{FIRMLY GRASP THE IMPORTANT TASK OF "2011 PLAN" IMPLEMENTATION}

The key task is to build the collaborative innovation platform and mode for the establishment of its mechanism and system to promote in depth cooperation between college, research institutes, industries and enterprises, local governments and the international community; college should explore a new mode on the collaboration of talent team construction, discipline construction and scientific research and the innovation in mechanism system, to form the 2011 Collaborative Innovation Center that can effectively serve the major national needs.

\subsection{To establish 2011 planning leading group and the working group}

College should set up the "2011 plan" leading group led by the main leadership and the expert group composed by the well-known academic leaders, who are responsible for the top-level design, overall coordination, funding and other major decisionmaking. At the same time, they should set up the "2011 plan" secretary group by the functional department, who are responsible for the reform of cooperative innovation system and mechanism and internal and external coordination of collaborative innovation center. College should promote the change scientific research development mechanism, to form a new scientific development mode with the collaborative innovation center to drive the overall development of scientific research in college.

\subsection{To establish the "2011 Collaborative Innovation Center" and to promote the development mechanism change of scientific research in college}

College should combine with the advantage disciplines to construct a number of collaborative innovation center and establish special funds to support the centers construction. For collaborative innovation centers that are approved, college should give full policy support and protection, implement academic zone and talent special area policies, to give relative autonomy in personnel recruitment and evaluation system, personnel training mechanism, the international cooperation and exchanges. They should give them focus and inclined support in outstanding talent planning, professional learning and exchange and other resources allocation.

\subsection{To find a new growth point of discipline, re- layout disciplines}

College should play the cross advantages of multidisciplines by the collaborative innovation center on the base of campus integration, which can form a new growth point in the discipline through the complementary advantage of the subject direction with other universities and enterprises, on the basis of traditional advantage disciplines, with major national demand for traction, to promote the relayout of university disciplines and university scientific research innovation ability.

\section{REFERENCES}

[1] Fu Guohui. On the status of college and university scientific research in discipline construction. Journal of Jiangxi Electric Power Vocational Technology College, 2010, (2): 66-68.

[2] Yang Guixia. Policy analysis on the comprehensive, balanced and sustainable development local colleges and universities from the perspective of scientific outlook on development. Education and Occupation, 2010676 (36): 183.

[3] Zhang Jinfeng, The status and trends of China's higher education reform and development. Journal of Zhejiang Shuren University, 2007 (3) 